\title{
Continuous low dose inhaled nitric oxide for treatment of severe pulmonary hypertension after cardiac surgery in paediatric patients
}

\author{
Maurice Beghetti, Walid Habre, Beat Friedli, Michel Berner
}

\begin{abstract}
Objective-To assess the effect of inhaled nitric oxide (NO) on severe postoperative pulmonary hypertension in children after surgical repair of a congenital heart defect.
\end{abstract}

Design-A pilot study of NO administration to 7 consecutive children who required adrenergic support and in whom postoperative mean pulmonary artery pressure was more than two thirds of mean systemic pressure and persisted despite alkalotic hyperventilation.

Setting-Routine care after cardiac surgery for congenital heart disease in a multidisciplinary paediatric intensive care unit.

Methods-Continuous inhalation of NO, initially at $15 \mathrm{ppm}$. Thereafter, daily attempts at complete weaning or at reducing NO to the lowest effective dose. Results-In 6 of the 7 children NO inhalation selectively decreased mean (SD) pulmonary artery pressure from 51 (12) to 31 (9) $\mathrm{mm} \mathrm{Hg}(\mathrm{P}<0.05)$ while mean systemic arterial pressure was unchanged (68 (10) $v 71$ (7) $\mathrm{mm} \mathrm{Hg}$ ) (NS) and the arteriovenous difference in oxygen content decreased from $6.7(0.9)$ to $4.8(0.8)$ vol\% (P < 0.05). Concomitantly $\mathrm{PaO}_{2}$ increased from 158 (98) to 231 (79) $\mathrm{mm} \mathrm{Hg})(\mathrm{P}<0.05)$. The seventh child showed no response to $\mathrm{NO}$ up to $80 \mathrm{ppm}$, could not be weaned from cardiopulmonary bypass, and died in the operating room. In responders, attempts at early weaning from NO inhalation always failed and NO at concentrations of less than 10 ppm was continuously administered for a median of 9.5 days (range 4 to 16 days) until complete weaning was possible from a mean dose of 3.9 (2.9) $\mathrm{ppm}$. Methaemoglobinaemia remained below $2 \%$ and nitrogen dioxide concentrations usually ranged from 0.1 to $0.2 \mathrm{ppm}$. One child later died and five were discharged. A few months after surgery Doppler echocardiography (and catheterisation in one) showed evidence of regression of pulmonary hypertension in all 5.

Conclusions-Inhalation of NO reduced pulmonary artery pressure in children with severe pulmonary hypertension after cardiac surgery and this effect was maintained over several days at concentrations carrying little risk of toxicity.

(Br Heart f 1995;73:65-68)
Keywords: inhaled nitric oxide, pulmonary hypertension, cardiac surgery, children.

Intractable pulmonary hypertension is a major cause of death in the immediate postoperative period after repair of congenital heart defects. In addition to preoperative factors, transient dysfunction of the endothelial cell after cardiopulmonary bypass could affect the physiology of nitric oxide (NO) release ${ }^{1}$ and such an effect has recently been implicated in the pathogenesis of pulmonary hypertension. ${ }^{23}$ During cardiac catheterisation in children, inhalation of NO for brief periods at doses of 20-80 ppm reduced the pulmonary vasoconstriction associated with left to right shunts. ${ }^{4}$ Continuous inhalation at lower doses for 24 hours decreased right to left ductal shunting in neonates with persistent pulmonary hypertension. ${ }^{56}$ There are occasional reports of NO resolving a postoperative hypertensive crisis. ${ }^{7-9}$ There is relunctance to administer inhaled NO in clinical conditions because of its potential toxic effects. ${ }^{10} \mathrm{NO}$ reacts with oxygen to form nitrogen dioxide at a speed that depends on the concentrations of the two gases, and inactivation of NO by haemoglobin can result in important methaemoglobinaemia.

In this pilot study we assessed whether inhalation of NO consistently reduced severe postoperative pulmonary hypertension and whether the concentrations of NO could be kept in a safe range for as long as NO treatment was needed.

Patients and methods

All patients were referred to our centre for elective cardiac surgery; those older than a year were referred from abroad. Two patients had Down's syndrome. Children with congenital heart disease and left to right shunts require an investigation of their pulmonary vascular bed before surgery is planned. We used oxygen consumption derived from a nomogram to estimate cardiac output (from the Fick equation) during cardiac catheterisation and to calculate pulmonary vascular resistance. We used the ratios of pulmonary to systemic vascular resistance ( $R p / R s)$ and of the respective blood flows $(\mathrm{Qp} / \mathrm{Q} s)$ as indices of the severity of pulmonary vascular disease to decide upon operability. Postoperatively, management of pulmonary hypertension has so far included hyperventilation induced alkalosis and pharmacological alteration of pulmonary vascular resistance by epoprostenol and tolazoline. 
Preoperative characteristics, postoperative course, and outcome of patients

\begin{tabular}{|c|c|c|c|c|c|c|c|c|c|}
\hline Case & $\begin{array}{l}\text { Age } \\
\text { (mnth) }\end{array}$ & $\begin{array}{l}\text { Heart } \\
\text { defect }\end{array}$ & \multicolumn{2}{|c|}{$\begin{array}{l}\text { Preoperative } \\
P V R \quad R p / R s\end{array}$} & $\begin{array}{l}\text { Initial } \\
\text { response } \\
\text { to NO }\end{array}$ & \multicolumn{3}{|c|}{$\begin{array}{l}\text { Mean dose of NO (ppm) } \\
\text { Day } 2 \text { Day } 4 \text { Last day }\end{array}$} & $\begin{array}{l}\text { Long-term } \\
\text { outcome }\end{array}$ \\
\hline $\begin{array}{l}1 \\
2 \\
3 \\
4 \\
5 \\
6 \\
7 \\
7\end{array}$ & $\begin{array}{l}16 \\
8 \\
24 \\
12 \\
12 \\
6 \\
168\end{array}$ & $\begin{array}{l}\text { VSD,PDA } \\
\text { ECD* } \\
\text { VSD } \\
\text { TA } \\
\text { ECD } \\
\text { ECD* } \\
\text { VSD }\end{array}$ & $\begin{array}{l}\text { NA } \\
4 \cdot 3 \\
14 \cdot 1 \\
5 \cdot 9 \\
6 \cdot 4 \\
8 \cdot 3 \\
9 \cdot 3\end{array}$ & $\begin{array}{l}\text { NA } \\
0.21 \\
0.45 \\
0.25 \\
0.71 \\
0.66 \\
0.34\end{array}$ & $\begin{array}{l}+ \\
+ \\
+ \\
+ \\
+ \\
+ \\
+\end{array}$ & $\begin{array}{l}8.5 \\
13 \\
10 \\
8 \cdot 5 \\
10 \\
8.5 \\
-\end{array}$ & $\begin{array}{l}3.0 \\
9 \cdot 0 \\
1.2 \\
1.8 \\
8.0 \\
7.5 \\
-\end{array}$ & $\begin{array}{l}3.0 \\
5.0 \\
6.0 \\
1.1 \\
8.0 \\
0.6 \\
-\end{array}$ & $\begin{array}{l}\text { Died } \\
\text { Lived } \\
\text { Lived } \\
\text { Lived } \\
\text { Lived } \\
\text { Lived } \\
\text { Died }\end{array}$ \\
\hline
\end{tabular}

PVR, preoperative pulmonary vascular resistance $\left(\mathrm{mm} \mathrm{Hg} / \mathrm{lmin} / \mathrm{m}^{2}\right) ; \mathrm{Rp} / \mathrm{Rs}$, preoperative pulmonary to systemic vascular resistance ratio; VSD, ventricular septal defect; PDA, patent ductus arteriosus; NA, not available (echocardiographic assessment); ECD, endocardial cushion defect ( Down' syndrome); TA, truncus arteriosus.

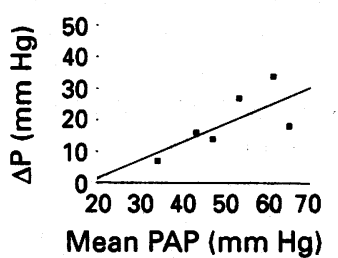

Figure 1 Relation between mean pulmonary artery pressure before NO inhalation was started and the drop in pulmonary pressure $(\triangle P)$ seen while patients inhaled $15 \mathrm{ppm}$ of NO $(\triangle P=0.60$ $P A P-1, R^{2}=0.51$, $P<0.05)$.

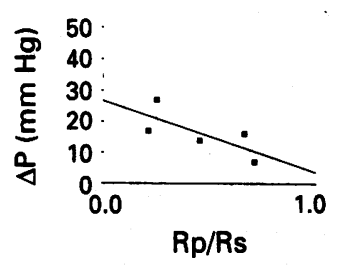

Figure 2 Relation between preoperative pulmonary to systemic resistance ratio (Rp/Rs) at catherisation and the drop in pulmonary pressure $(\triangle P)$ seen after operation in patients inhaling 15

ppm of NO. ( $\triangle P=-22$

$R p / R s+26, R^{2}=0.53$, $P=0.07)$.
After we found that NO inhalation was helpful in an infant with severe pulmonary hypertension our institutional review board sanctioned the use of NO treatment after surgical repair of congenital heart disease in children with left to right shunts who had: (a) a mean pulmonary artery pressure that remained consistently higher than $2 / 3$ of mean systemic pressure despite alkalotic hyperventilation at $\mathrm{a} \mathrm{pH}$ over 7.45 and $(b)$ who had clinical evidence of low output syndrome requiring adrenergic support.

We administered NO (350 ppm in nitrogen, AGA, Pratteln, Switzerland) through the inspiratory limb of a continuous flow, time cycled, pressure limited ventilator (Babylog 8000, Drager AG, Lubeck, Germany). The NO concentration was regulated through a precision flow meter and mixed with the constant flow of the ventilator usually at $20 \mathrm{~V} / \mathrm{min}$. NO and nitrogen dioxide concentrations were verified intermittently by chemiluminescence (CLD 700 AL, Eco Physics AG, Durnten, Switzerland) before they entered the $\mathrm{Y}$ piece.

We started with 15 ppm NO: if this proved successful we gave the same concentration until the next day, when we first attempted to wean the patient off NO. If there was a rebound in pulmonary hypertension with a decrease in systemic pressure, NO inhalation was resumed at the lowest possible dose capable of maintaining the pulmonary pressure at preweaning values. Each day we attempted weaning, using the same protocol, until complete withdrawal was possible. Ventilation was adapted to keep the pH around $\mathbf{7 \cdot 4 5}$. Adrenergic support was progressively reduced as systemic pressure and diuresis improved. No other vasodilators were used while NO was given or during weaning off NO.

Between two and five months after discharge from the hospital we assessed the result of surgery and measured residual pulmonary hypertension by Doppler echocardiography and, if the result seemed abnormal, by catheterisation.

\section{STATISTICAL ANALYSIS}

We used a paired sample $t$ test to assess the effects of NO inhalation and linear regression analysis to analyse the relation between variables and the effect of NO on pulmonary pressure. A P value of $<0.05$ was regarded as significant. ${ }^{11}$

\section{Results}

The table shows the characteristics of the seven consecutive patients. Before operation pulmonary vascular resistance was increased in all children, with values ranging from 4.3 to $14.1 \mathrm{~mm} \mathrm{Hg} / 1 / \mathrm{min} / \mathrm{m}^{2}$. After operation pulmonary hypertension was present as soon as the patients came off cardiopulmonary bypass. All patients had signs of right ventricular failure requiring inotropic support (five with adrenaline $(0.8(0.1) \mu \mathrm{g} / \mathrm{kg} / \mathrm{min})$ and two with dobutamine $(15 \mu \mathrm{g} / \mathrm{kg} / \mathrm{min})$. In addition, in three children, the pericardium and thorax had to be left open. All children were given dopamine $(5 \mu \mathrm{g} / \mathrm{kg} / \mathrm{min})$. Mean fractional inspired ogygen was $0.81(0.25)$ and a raised mean minute ventilation of 2136 (537) $\mathrm{ml} / \mathrm{min}$ was required to maintain a mean $\mathrm{pH}$ of $7.48(0.03)$. In six of the seven children, inhalation of NO resulted in an immediate decrease in mean pulmonary arterial pressure from a mean of 51 (12) to 31 (9) $\mathrm{mm} \mathrm{Hg} \mathrm{(P<}$ $0.05)$ without any change in mean systemic arterial pressure $(68(10) v 71(7) \mathrm{mm} \mathrm{Hg}$ ). The drop in pulmonary artery pressure $(\Delta P)$ with NO correlated positively with the postoperative mean pulmonary artery pressure (PAP) (fig 1) and showed a tendency to an inverse correlation with the preoperative systemic to pulmonary resistance ratio $(\Delta \mathrm{P}=$ $-22 R p / R s+26, R^{2}=0.53, P=0.07$ ) (fig 2). In one patient, who had a thermodilution catheter in place, the pulmonary blood flow increased from 1.5 to $1.8 \mathrm{l} / \mathrm{min}$. In the five other children, the arteriovenous difference in oxygen content decreased from $6.7(0.9)$ to $4.8(0.8)$ vol\%, $\mathrm{P}<0.05 . \mathrm{PaO}_{2}$ increased from 158 (98) to 231 (79) $\mathrm{mm} \mathrm{Hg}(P<0.05$ with little change in $\mathrm{FIO}_{2}(0.81(0.25)$ to 0.70 $(0 \cdot 23)$ NS). There was no significant decrease in $\mathrm{PaCO}_{2}$ (31 (9) to 27 (5) $\mathrm{mm} \mathrm{Hg}$, NS) and minute ventilation was unchanged (2136 (537) v 2036 (463) $\mathrm{ml} / \mathrm{min}$ ). Attempts to wean all the children off NO after 24 hours failed, resulting in an immediate increase in pulmonary arterial pressure (32 (5) to 51 (5) $\mathrm{mm} \mathrm{Hg}, \mathrm{P}<0.05$ ) with a concomitant decrease in mean systemic arterial pressure from 64 (6) to 57 (6) $\mathrm{mm} \mathrm{Hg}(P<0.05)$, both effects resolved when inhalation of NO was resumed. Figure 3 shows the effect of introducing NO on both pulmonary and systemic arterial pressures and the first attempt at weaning off $\mathrm{NO}$ after 24 hours in the six responders. The lowest concentrations of NO able to maintain pulmonary artery pressure at preweaning values after 24 hours were all below $15 \mathrm{ppm}$ and averaged $9.9(1.8) \mathrm{ppm}$ on day 2 and $5.4(4.0)$ ppm on day 4 . Maintenance of inhaled NO at concentrations as low as $0.8 \mathrm{ppm}$ was occasionally effective (fig 4): in one patient, NO was given through nasal prongs after extubation. Complete weaning from a mean dose of $3.9(2.9)$ ppm was achieved after a median of 9.5 days (range 4-16) in all patients. In the two 
Figure 3 Changes (mean (SEM)) of mean

pulmonary arterial pressure (O) and mean systemic arterial pressure ( $\square$ ), in six "responders". On the left, inital effect of inhaled NO, on the right, changes seen during the first attempt at weaning off $N O$ and resuming $N O$ at the next day. ${ }^{\star} P<0.05$ same concentration on the

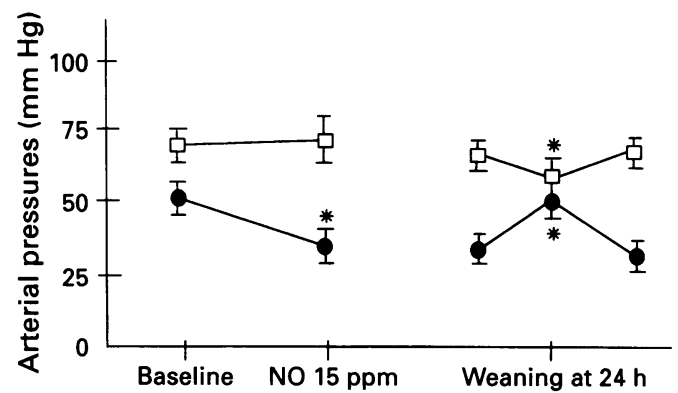

patients in whom the thorax had to be left open after surgery the chest eventually could be closed.

Patient 7 could not come off cardiopulmonary bypass and administration of NO was started in the operating room. Despite inhalation of concentrations from 15 up to $80 \mathrm{ppm}$, pulmonary artery pressure remained equal to systemic pressure and both were around 40 $\mathrm{mm} \mathrm{Hg}$ despite massive adrenergic support. The child eventually died and a lung biopsy specimen showed advanced vascular disease with recanalisation of obliterative lesions and a chronic interstital pneumonitis.

The level of methaemoglobinaemia was always $<2 \%$ and nitrogen dioxide concentrations measured in the expiratory circuit rarely exceeded $0.5 \mathrm{ppm}$ (range $0.1-0.2 \mathrm{ppm}$ ). One patient later died of a cause unrelated to cardiovascular pathology. The five patients discharged from the hospital were evaluated 2-5 months after operation and showed good results. Of the three with preoperative signs of severe pulmonary artery hypertension two had a decrease in systolic pulmonary pressure estimated from tricuspid regurgitation at echocardiography (from 78 to $45 \mathrm{~mm} \mathrm{Hg}$ and 60 to $40 \mathrm{~mm} \mathrm{Hg}$ respectively) and one showed a decrease in $\mathrm{Rp} / \mathrm{Rs}$ at catheterisation
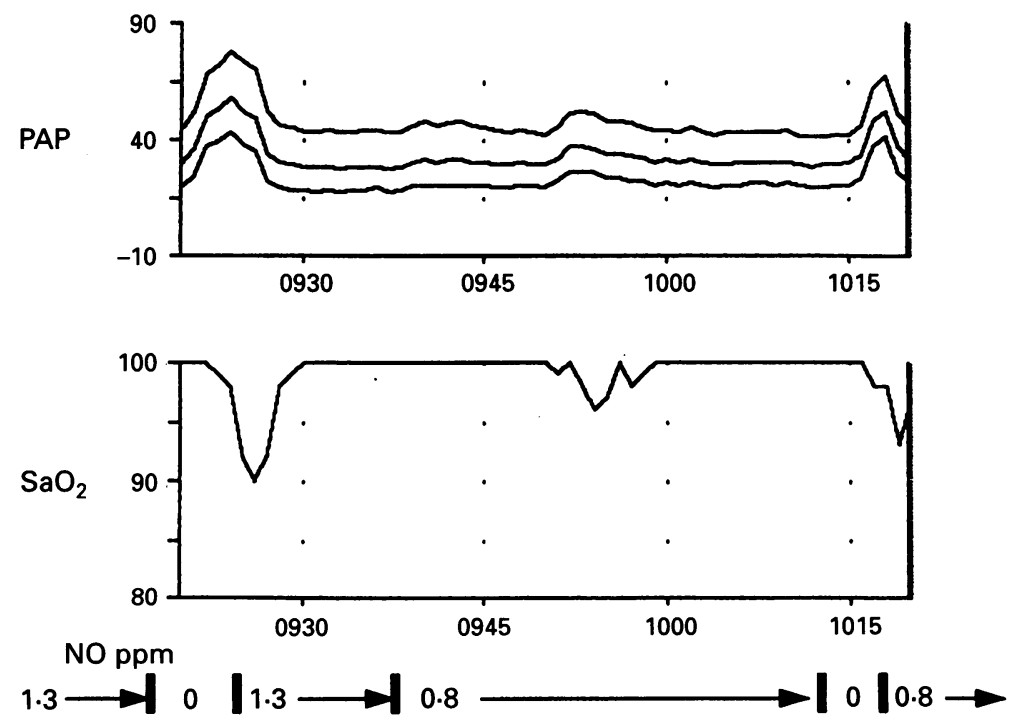

Figure 4 Recording of pulmonary artery pressure (systolic, mean, diastolic) and arterial oxygen saturation ( $\mathrm{SaO}_{2}$ ) during successive failures at weaning attempts from $\mathrm{NO}$ at 1.3 $\mathrm{ppm}$ and after a further decrease to $0.8 \mathrm{ppm}$. Both failures are manifested by the immediate rise in pulmonary artery pressure and drop in systemic $\mathrm{SaO}_{2}$. Resolution quickly followed reinstitution of NO at the earlier dose. from 0.45 to 0.33 . In the two last patients, either $\mathrm{Rp} / \mathrm{Rs}(0.31)$ or systolic pressure $(40$ $\mathrm{mm} \mathrm{Hg}$ ) resembled the preoperative value.

\section{Discussion}

In this pilot study low doses of inhaled NO consistently reduced severe postoperative pulmonary hypertension in children after repair of congenital heart defects. In such patients NO has the advantage of selectively causing pulmonary vasodilation, with a rapid decrease in right ventricular afterload, rather than improving the ventilation perfusion mismatch. None the less, the rise in $\mathrm{PaO}_{2}$ described in patients with diffuse lung injury ${ }^{12}$ was also seen. An increase in pulmonary blood flow was measured in one child who had a thermodilution catheter in place and was indicated in the other patients by a significant decrease in the arteriovenous oxygen content difference. Overall haemodynamic improvement was later indicated by the progressive ability to withdraw adrenergic support. All these effects accord with the recent findings of Wessel et al who showed that much of the increase in pulmonary vascular resistance after cardiac surgery is related to endothelial cell dysfunction and that it can be overcome by treatment with $\mathrm{NO}^{2}$ Additional support for this hypothesis comes from the significant drop in pulmonary pressure that followed NO treatment and correlated positively with the height of postoperative pulmonary artery pressure. This drop tended to correlate negatively with the preoperative pulmonary to systemic vascular resistance ratio. In our patients, these effects were induced by lower concentrations than described previously ${ }^{24}$ and often, only minute amounts (1 to $4 \mathrm{ppm}$ ) were required to maintain low pulmonary artery pressure. Low doses of NO were also effective in lung diseases. ${ }^{13}$

Our selection criteria were defined to apply to children with the most severe postoperative pulmonary hypertension that did not respond to alkalosis-induced pulmonary vasodilation, which has been shown to act independently of the NO pathway. ${ }^{14}$ Indeed, we encountered pulmonary hypertension resistant to NO: concentrations up to $80 \mathrm{ppm}$ for one hour were not able to decrease pulmonary pressure in one child with advanced obliterative vascular disease who died in the operating room. A progressive decline in the vasodilator response of the pulmonary vascular bed first to acetylcholine ${ }^{15}$ and later to nitrous vasodilators was seen in children with advanced pulmonary vascular disease. Nevertheless, a test with NO, even at high doses, can be attempted because there is no risk of a drop in systemic pressure. Also in future, combination of NO with other vasodilators might prove beneficial, as suggested by the simultaneous administration of NO and epoprostenol. ${ }^{9}$

Unlike the report of an earlier case, ${ }^{8}$ attempts at abrupt weaning in the first 24 hours failed in all these children and resulted in a considerable rise in pulmonary artery pressure within minutes accompanied by a fall 
in systemic arterial pressure. This meant that during tracheal suctioning a second delivery system had to be used to administer NO. The decision of when and how to attempt weaning is arbitrary. In all cases a tolerable increase in pulmonary artery pressure without systemic haemoglobin desaturation or a drop in systemic pressure was seen only after several days and when the dose of NO had been low. In one case after extubation administration of NO was continued through nasal prongs and was well tolerated. There are two possible explanations why weaning from administration had to be done gradually: (a) a possible down-regulation of the endogenous production of NO once inhalation has been started, ${ }^{16}$ and $(b)$ progressive recovery from the cell dysfunction over several days. ${ }^{2}$

The dose of inhaled NO that reduced and maintained low pulmonary artery pressure was well below the $25 \mathrm{ppm}$ allowed by the National Institute for Occupational Safety and Health. ${ }^{17}$ Concentrations of methaemoglobulin were measured daily and never reached clinically important values. However, the toxicity of NO is mostly associated with its transformation into nitrogen dioxide which can damage the lungs. Low doses of NO and high ventilator flow rates minimises the residence time of the $\mathrm{NO} / \mathrm{O}_{2}$ mixture in the ventilator circuitry. Nitrogen dioxide concentrations rarely exceeded $0.5 \mathrm{ppm}$, which is 10 times lower than the upper limit tolerated. ${ }^{18}$ The concentrations of 0.1 to $0.2 \mathrm{ppm}$ of nitrogen dioxide that we recorded are commonly detected in the ambient air of many western industrial cities during the winter. ${ }^{19}$

Pulmonary hypertension resolved in six of seven patients given NO. One child later died from an episode of severe anoxia unrelated to his cardiovascular pathology. The five other patients were discharged. All were doing well clinically and showing signs of regression of their pulmonary hypertension at echocardiography or catheterisation several months later.

Low doses of inhaled NO reduced pulmonary hypertension after cardiac surgery in most of these patients. This treatment for a potentially life threatening condition carried little risk of toxicity. This knowledge should help workers to design clinical trials to assess the place of inhaled NO in the complex treatment of pulmonary hypertension after cardiac surgery in children.

1 Moncada S, Palmer RMJ, Higgs EA. Nitric oxide: physiology, pathophysiology and pharmocaology Pharmacological Rev 1991;43:108-42.

2 Wessell DL, Adatia I, Giglia TM, Thompson JE, Kulik TJ. Use of inhaled nitric oxide and acetylcholine in the evaluation of pulmonary hypertension and endothelial function after cardiopulmonary bypass. Circulation 1993 88:2128-38.

3 Celermajer DS, Cullen S, Deanfield JE. Impairment of endothelium-dependent pulmonary artery relaxation in children with congenital heart disease and abnormal in children with congenital heart disease and abnormal
pulmonary hemodynamics. Circulation 1993;87:440-6.

4 Roberts JD, Land P, Bigatello L, Vlahakes G, Zapol WM Inhaled nitric oxide in congenital heart disease. Inhaled nitric oxide in

5 Roberts JD, Polaner DM, Lang P, Zapol WM. Inhaled nitric oxide in persistent pulmonary hypertension of the newborn. Lancet 1992;340:818-9.

6 Kinsella JP, Neish SR, Ivy DD, Shaffer E, Abman SH Clinical responses to prolonged treatment of persisten pulmonary hypertension of the newborn with low dose inhaled nitric oxide. $\mathcal{Y}$ Pediatr 1993;123:103-8.

7 Berner M, Beghetti M, Ricou B, Rouge JC, Prêtre R Friedli B. Relief of severe pulmonary hypertension after closure of a large ventricular septal defect using low dose inhaled nitric oxide. Intensive Care Med 1993;19. 75-7.

8 Sellden $H$, Winberg P, Gustafsson LE, Lundell B, Böök $\mathrm{K}$, Frostell $\mathrm{K}$. Inhalation of nitric oxide reduced pulmonary hypertension after cardiac surgery in a 3.2-kg infant. Anesthesiology 1993;78:577-80.

9 Schranz D, Huth R, Wippermann CF, Ritzerfeld S, Schmitt FX, Oelert H. Nitric oxide and prostacyclin Schmitt FX, Oelert H. Nitric oxide and prostacyclin
lower suprasystemic pulmonary hyperternsion lower suprasystemic pulmonary hyperternsion
after cardiopulmonary bypass. Eur $\mathcal{f}$ Pediatr 1993;152: after cardi.

10 Frostell CG, Frattacci MD, Wain JC, Jones R, Zapol WM. Inhaled nitric oxide. A selective pulmonary vasodilator reversing hypoxic pulmonary hypertension. Circulation 1992;83:2038-47.

11 Zar JH. Biostatistical analysis. 2nd ed. Prentic-Hall: Englewood Cliffs, NJ. 1974;150-2.

12 Rossaint R, Falke KJ, Lopez F, Slama K, Pison U, Zapol WM. Inhaled nitric oxide for the adult respiratory distress syndrome. $N$ Engl $f$ Med 1993;328: $399-405$.

13 Gerlach H, Rossaint R, Pappert D, Falke KJ. Time-course and dose-response of nitric oxide inhalation for systemic oxygenation and pulmonary hypertension in patients with adult respiratory distress syndrome. Eur $\mathfrak{f}$ Clin with aduit respiratory dist

14 Fineman JR, Wong J, Soifer SJ. Hyperoxia and alkalosis produce pulmonary vasodilation independent of endothelium-derived nitric oxide in newborn lambs. Pediatr Res 1993;33:341-6.

15 Dinh Xuan AT, Higenbottam TW, Clelland C, PepkeZaba J, Cremona G, Wallwork J. Impairment of pulmonary endothelium-dependent relaxation in patients with Eisenmenger's syndrome. Br $\mathcal{F}$ Pharmacol 1989;99:9-10.

16 Buga GM, Griscavage JM, Rogers NE, Ignarro LJ Negative feedback regulation of endothelial cell function by nitric oxide. Circ Res 1993;73:808-12.

17 Center For Disease Control. NIOSH recommendations for occupational safety and health standards. MMWR Morb Mortal Wkly Rep 1988;37:S-7(21).

18 Foubert Fleming B, Latimer R, Jonas M, Oduro A Borland C, et al. Safety guidelines for use of nitric acid Borland C, et al. Safety guideling

19 Notre air Technique et environnement. Touring Club de Suisse: Emmen 1992, p21. 